\title{
Numerical Imbalances of Chromosome 7 in Oral Squamous Cell Carcinoma
}

\author{
NICHOLAS S. MASTRONIKOLIS ${ }^{1}$, EVANGELOS TSIAMBAS ${ }^{2}$, PANAGIOTIS P. FOTIADES ${ }^{3 *}$, \\ EVANGELIA BALIOU ${ }^{4 *}$, ANDREAS KARAMERIS ${ }^{2}$, DIMITRIOS PESCHOS ${ }^{5}$, STYLIANOS N. MASTRONIKOLIS ${ }^{6}$, \\ ASIMAKIS D. ASIMAKOPOULOS ${ }^{7}$, XENOFON GIANNAKOPOULOS $^{8}$ and VASILEIOS RAGOS ${ }^{9}$ \\ ${ }^{1}$ ENT Department, Medical School, University of Patras, Patras, Greece; \\ ${ }^{2}$ Department Pathology/Cytopathology, 417 VA Hospital, Athens, Greece; \\ ${ }^{3}$ Department of Surgery, Leicester General Hospital, Leicester, U.K.; \\ ${ }^{4}$ Department of Pathology, Hippokrateion Hospital, Athens, Greece; \\ ${ }^{5}$ Departments of Physiology, ${ }^{8}$ Urology, and ${ }^{9}$ Maxillofacial, Medical School, University of Ioannina, Ioannina, Greece; \\ ${ }^{6}$ Department of Medicine, School of Health Sciences, University of Crete, Heraklion, Crete; \\ ${ }^{7}$ ENT Department, Luxembourg Hospital Center, Luxembourg, Luxembourg
}

\begin{abstract}
Background: Oral squamous cell carcinoma (OSCC) is an aggressive neoplasm. Many chromosomal and gene alterations have been identified in OSCC, including structural and numerical changes. In this study, we implemented a molecular assay of chromosome 7 (Chr7) in order to investigate the level of its numerical instability in OSCC. Materials and Methods: Using tissue microarray technology, 30 primary OSCCs were cored and re-embedded into one recipient block. Chromogenic in situ hybridization assay was performed based on Chr7 centromeric probedetection. Results: Chr 7 numerical analysis detected polysomy (trisomy/ tetrasomy) in 4/30 (13.3\%) of the examined tissue OSCC cores. Statistical significance was assessed correlating Chr7 numerical aberrations with stage $(p=0.015)$, especially detected in cases not related to human papillomavirus (HPV) $(p=0.01)$. Conclusion: Although Chr7 polysomy is a relatively rare gross genetic event in OSSC, it affects their biological behavior leading toa progressively aggressive phenotype (advanced stage). Furthermore, Chr7 polysomy is observed more frequently in non-viral (HPV) cases.
\end{abstract}

\footnotetext{
*These Authors contributed equally to this study.

Correspondence to: Evangelos Tsiambas, MD, MSc, Ph.D., Department of IHC \& Molecular Biology, 401 GAH, Medical School, University of Athens, 17 Patriarchou Grigoriou E' Street, Ag. Paraskevi, 15341 Athens, Greece. Mobile: +306946939414 , email: tsiambasecyto@yahoo.gr
}

Key Words: Squamous cell carcinoma, oral cavity, microarrays, chromosome7, in situ hybridization.
Malignancies involving the oral cavity and oropharynx demonstrate an increasing rate worldwide. In particular, oral squamous cell carcinoma (OSSC) represents a significant proportion (50-55\%) of head and neck squamous cell carcinomas (1). OSSC is characterized by an aggressive phenotype including poor prognosis, moderate response rates to chemoradiotherapy and targeted therapeutic agents, such as monoclonal antibodies $(2,3)$. Pre-malignant histology in oral epithelia corresponds predominantly to erythroplakia and lesser to leukoplakia (4). During carcinogenesis, oral epithelia accumulate gross chromosomal (gains and losses) and specific gene (mutations, allelic losses, amplifications) deregulations driving them to a neoplastic and finally malignant transformation (5). Chromosome instability is a frequent genetic event in those solid malignancies (6). Among all chromosomes, chromosome 7 (Chr7) seems to play a critical role in OSSC initiation and progression due to erythroplakia/leukoplakia and dysplastic epithelia. Aberrations in significant genes located on it, such as epidermal growth factor receptor (EGFR) mesenchymal-epithelial transition factor (MET), and murine sarcoma viral oncogene homolog B $(B R A F)$ combined with numerical abnormalities of the whole chromosome are cytogenetic events that lead to specific molecular signatures in the corresponding patients $(7,8)$. In the current study, we analyzed numerical aberrations of $\mathrm{Chr} 7$ implementing chromogenic in situ hybridization (CISH) on OSSC cores embedded in tissue microarrays (TMAs).

\section{Materials and Methods}

Study group. For the purposes of our study, 30 archival, formalin-fixed and paraffin-embedded tissue specimens of histologically-confirmed primary OSSCs were used. The hospital Ethics Committee consented to the use of these tissues in the Department of Pathology, 417VA 
Hospital (NIMTS), for research purposes, according to the World Medical Association Declaration of Helsinki guidelines. The tissue samples were fixed in $10 \%$ neutral-buffered formalin. Hematoxylin and eosin (H\&E)-stained slides of the corresponding samples were reviewed for confirmation of histopathological diagnoses. All lesions were classified according to the histological typing criteria of World Health Organization (WHO) (9). Clinicopathological data of the examined cases are demonstrated in Table I.

TMA construction. Areas of interest were identified in H\&E-stained slides by a conventional microscopy (Olympus BX-50; Olympus Corp, Melville, NY, USA). Selection of these areas was performed on the basis of tumor sufficiency, avoiding sites of necrosis or bleeding. Using ATA-100 apparatus (Chemicon International, Temecula, CA, USA), all of the source blocks were cored twice. In order to secure the presence of each case, two 0.6-mm diameter tissue cylindrical cores were transferred from each conventional donor block to the recipient block. After $4-\mu \mathrm{m}$ microtome sectioning and $\mathrm{H} \& \mathrm{E}$ staining, we observed microscopically that all examined OSSC cases were represented by at least one or two tissue spots (confirmation of the adequacy of the examined specimens). Five $(n=5)$ cores of microscopically normal oral squamous epithelia (controls) inside the examined tissue sections were also embedded in the block.

CISH. CISH SPOT-Light Chromogenic ISH Detection Kit (Zymed/Invitrogen, San Fransisco, CA, USA) was applied. CISH for Chr7 numerical status analysis of was performed on 6- $\mu$ m-thick paraffin serial section of the TMA block described above. One slide was incubated at $37^{\circ} \mathrm{C}$ overnight followed by $2 \mathrm{~h}$ incubation at $60^{\circ} \mathrm{C}$ and then deparaffinized in xylene twice, 5 min each and in ethanol three times, 3 min each. The slide was then rinsed in deionized water and placed in a coplin jar containing CISH FFPE Pretreatment Buffer (CISH Tissue Pretreatment Kit; Zymed/InVitrogen, USA). For heat pre-treatment, the coplin jar was capped, loosely screwed, placed in a pressure cooker and timed for $10 \mathrm{~min}$ after the pressure built up. The slide was then immediately washed in deionized water followed by enzyme digestion, which was performed by covering the sections with pepsin for $5 \mathrm{~min}$ at $37^{\circ} \mathrm{C}$. The slide was washed with deionized water, dehydrated with graded ethanol and air-dried. Ready to use biotin-labeled chromosome 7 centromere probe (CEP) (Zymed/Invitrogen) was selected for the analysis. Twenty $(n=20)$ microliters of probe was applied to the TMA section. The tissue section containing the added probe was denatured by placing the slide in a polymerase chain reaction (PCR) machine equipped with a slide block at $94^{\circ} \mathrm{C}$ for $5 \mathrm{~min}$. The slide was then placed in a moist slide box and incubated at $37^{\circ} \mathrm{C}$ for overnight hybridization. The section was stringently washed in $0.5 \mathrm{x}$ standard saline citrate at $75^{\circ} \mathrm{C}$ for $5 \mathrm{~min}$. CISH Polymer and Horseradish (HRP) Detection Kit (Zymed/Invitrogen) using similar steps to immunohistochemistrywere used. Shortly, afterwards TMA section was placed in $3 \% \mathrm{H}_{2} \mathrm{O}_{2}$ and diluted with methanol for 10 min to block endogenous peroxidase. To block nonspecific staining, Cas Block ${ }^{\mathrm{TM}}$ (Zymed/Invitrogen) was applied and slides incubated for a further $10 \mathrm{~min}$. Following incubation, the biotin labeled CEP was detected by incubation with HRP-conjugated streptavidin for $30 \mathrm{~min}$, followed by DAB development (CISH Centromere Detection Kit; Zymed/Invitrogen) for $30 \mathrm{~min}$. TMA sections were lightly counterstained with hematoxylin and dehydrated in graded ethanol. At the end of the process, CISH centromere signals were easily visualized as dark brown scattered dots, using a conventional, bright-field microscope. Interpretation of CEP copy results was based on Zymed's Evaluation Chart for CISH. According
Table I. Clinicopathological parameters and total chromosome 7 centromeric probe (CEP7) signals in chromogenic in situ hybridization results for patients with oral squamous cell carcinoma.

\begin{tabular}{|c|c|c|c|c|}
\hline \multirow[b]{2}{*}{ Parameter } & & \multicolumn{3}{|c|}{ CEP7 numerical status } \\
\hline & & Diploid & Polysomy & $p$-Value \\
\hline All patients & $\mathrm{n}=30$ & $26(86.7 \%)$ & $4(13.3 \%)$ & \\
\hline Gender & & & & 0.192 \\
\hline Male & $18(60 \%)$ & $16(52.8 \%)$ & $2(6.6 \%)$ & \\
\hline Female & $12(40 \%)$ & $10(33 \%)$ & $2(6.6 \%)$ & \\
\hline Anatomical region & & & & 0.231 \\
\hline Oral cavity & $19(63.3 \%)$ & $17(56.1 \%)$ & $2(6.6 \%)$ & \\
\hline Oropharynx & $11(36.7 \%)$ & $9(29.9 \%)$ & $2(6.6 \%)$ & \\
\hline Grade & & & & 0.352 \\
\hline 1 & $10(33.3 \%)$ & $9(29.9 \%)$ & $1(3.3 \%)$ & \\
\hline 2 & $16(53.3 \%)$ & $14(46.6 \%)$ & $2(6.6 \%)$ & \\
\hline 3 & $4(13.3 \%)$ & $3(10 \%)$ & $1(3.3 \%)$ & \\
\hline Stage & & & & 0.015 \\
\hline I & $9(29.9 \%)$ & $9(29.9 \%)$ & $0(0 \%)$ & \\
\hline II & $9(29.9 \%)$ & $9(29.9 \%)$ & $0(0 \%)$ & \\
\hline III & $8(26.6 \%)$ & $5(16.6 \%)$ & $3(10 \%)$ & \\
\hline IV & $4(13.3 \%)$ & $3(10 \%)$ & $1(3.3 \%)$ & \\
\hline Smoking/HPV status & & & & 0.010 \\
\hline Smoking $^{+} / \mathrm{HPV}^{+}$ & $4(13.3 \%)$ & $4(13.3 \%)$ & $0(0 \%)$ & \\
\hline Smoking ${ }^{+} / \mathrm{HPV}^{-}$ & $22(73.3 \%)$ & $18(60 \%)$ & $4(13.3 \%)$ & \\
\hline Smoking $-\mathrm{HPV}^{+}$ & $3(10 \%)$ & $3(10 \%)$ & $0(0 \%)$ & \\
\hline Smoking ${ }^{-} / \mathrm{HPV}^{-}$ & $1(3.3 \%)$ & $1(3.3 \%)$ & $0(0 \%)$ & \\
\hline
\end{tabular}

Bold $p$-values indicate statistical significance.

to this guide, the numerical status of Chr7 is evaluated to determine aneuploidy/polysomy (3-5 centromeric signals per nucleus), diploid pattern (two centromeric signals per nucleus demonstrates normal chromosome status) or monosomy (one centromeric signal per nucleus). The predominant genetic event regarding overall spots for Chr7 per examined nucleus was assessed in $\geq 30 \%$ of the examined intact, not overlapping cells (Figure 1).

Statistical analysis. Associations between CISH signals and clinicopathological parameters were performed by applying Pearson chi-square test and Spearman correlation coefficient. Two-tailed $p$ values of 0.05 or less were considered statistically significant. Results are given in Table I.

\section{Results}

According to CISH CEP 7 numerical analysis, polysomy ( $>2$ signals per nucleus) was detected in $4 / 30$ (13.3\%) of the examined OSCC tissue cores. In three of them, Chr7 trisomy (three centromeric signals in $\geq 30 \%$ of cancerous nuclei) was identified, whereas in the last case $(n=1)$, tetrasomy (four centromeric signals in $\geq 30 \%$ of cancerous nuclei) was observed. Interestingly, overall $\mathrm{Chr} 7$ polysomy was correlated with cases not related to HPV infection $(p=0.01)$. Coanalyzing smoking and viral infection status, all CEP 7 polysomy cores were included in the group ofHPV-negative 


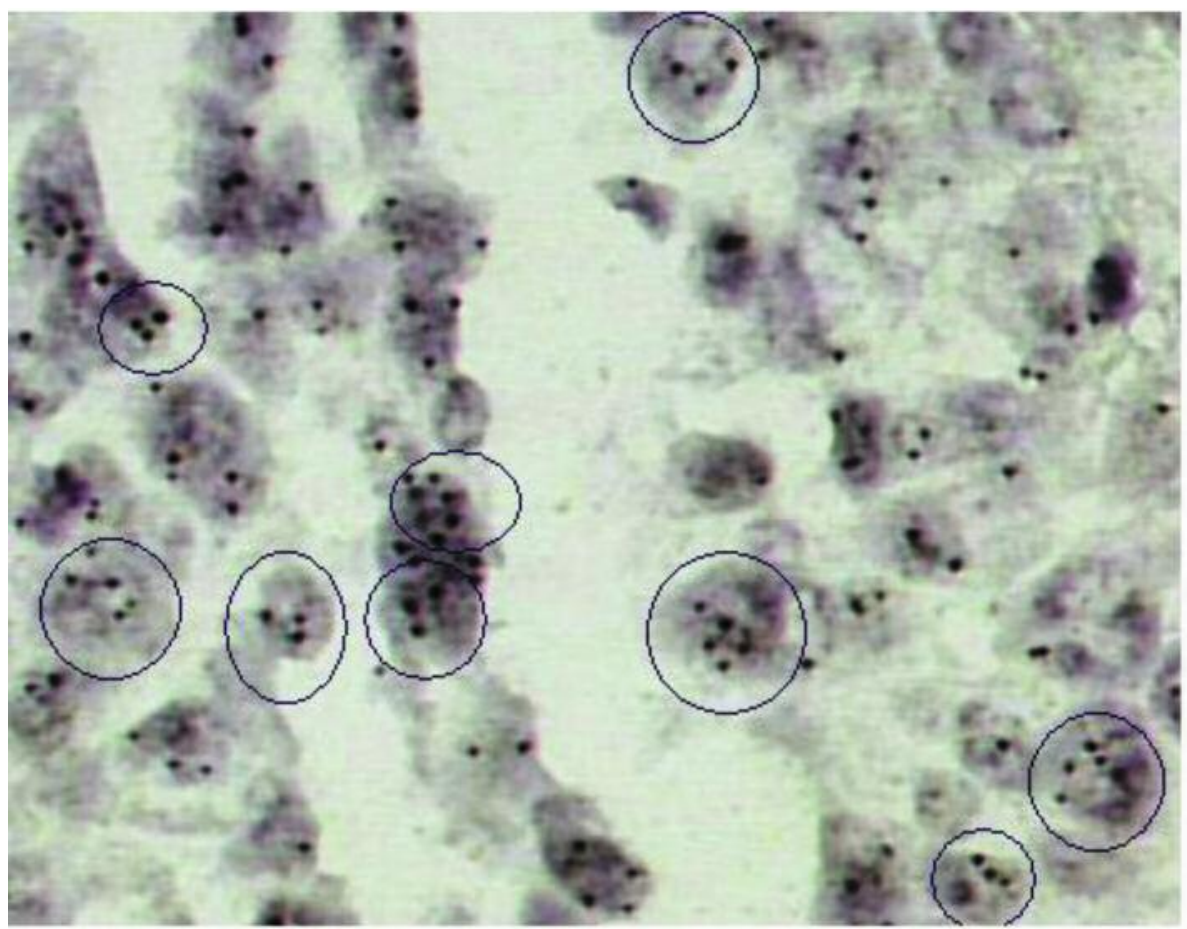

Figure 1. Chromogenic in situ hybridization analysis in a tissue core showing polysomy. Note 3-4 signals per nucleus in a sub-population of cancerous cells [abnormal nuclei inside circles; original magnification 400× (3,3'-diaminobenzidine) chromogen].

smokers $(n=22)$. Concerning the other clinicopathological features, statistical significance was assessed, finding correlation of overall Chr7 numerical imbalances only with stage of the corresponding malignancies $(p=0.015)$.

\section{Discussion}

Chronic exposure to tobacco smoke predominantly and alcohol consumption, combined or not with persistent infection with high-risk HPV, are major lifestyle and sexually transmitted factors implicated in oral epithelia carcinogenesis $(10,11)$. Extensive cytogenetic analyses have shown that there are distinct OSCC sub-groups based on specific genetic signatures $(12,13)$. Gross chromosomal instability is frequently detected in sporadic cases especially without viral infection, correlated with an aggressive phenotype (advanced stage, generally poor prognosis and moderate response rates to chemo-targeted therapies) (14). In contrast to OSCC dependent on chromosomal instability, other groups of patients demonstrate low to high specific gene allelic loses or gains combined or not with TP53 mutations and microsatellite instability (15). These genetic variants are more prominent in HPV-related OSCC, not only being associated with increased response rates to targeted and chemo-therapeutic agents, but also with a balanced prognosis $(16,17)$. Concerning the role of Chr7 in OSSC development and progression, it is well known that critical genes for signal transduction to the nucleus are located on it. Among them, EGFR (gene locus: 7p12, exons: 30), MET (gene locus: 7q31, exons: 24), and BRAF (gene locus: 7q34, exons: 22) are frequently deregulated in solid malignancies including lung, colon, and of course head and neck carcinomas $(18,19)$.

In the current study, we investigated the role of numerical aberrations of Chr7 in OSSC. Applying CISH technique to TMAs cores, we detected a sub-group of cases characterized by multiple centromeric copies of CEP7 (three to four per nucleus). Overall, Chr7 polysomy was correlated with advanced stage and also no HPV infection in the examined cases. Similar studies based on fluorescence in situ hybridization and also on comparative genomic hybridization have shown that gross chromosome structural or numerical aberrations affect a significant proportion of OSSCs, associated with some clinicopathological parameters (grade of differentiation, survival rates and overall prognosis) $(20,21)$. Referring to Chr7 polysomy, those study groups identified triploid and tetraploid cases, whereas an increased number of signals (five to six per nucleus) was extremely rare. During carcinogenesis, pure Chr7 polysomy (multiple CEP 7 copies) happens de novo or as a result of a progressively clonal rise and expansion inside the primary tumor micro-environment. Similar molecular studies based on chromosomaI analysis inlung cancer have confirmed this specific genetic event $(22,23)$. Furthermore, these genomic abnormalities interact with specific gene imbalances including 
losses or amplifications and point mutations forming distinct genetic patterns in patients. In fact, these genetic signatures in OSSC cases are in conjunction with specific high-risk factors described above (smoking status, chronic, persistent high-risk viral infection).

\section{Conclusion}

Chr7 deregulation due to polysomy, although relatively rare, plays a crucial role in OSSC increasing its biological aggressive behavior (advanced stage). Chromosomal instability related to numerical instability of $\mathrm{Chr} 7$ is more prominent in smokers and patients without HPV infection. Based on this and similar specific genetic imbalances, patients with OSSC are characterized by distinct genomic profiles leading to specific signatures that could allow for personalized targeted therapeutic management.

\section{Conflicts of Interest}

The Authors declare they have no conflicts of interest in regard to this study. No financial support was provided.

\section{References}

1 Parkin DM, Bray F, Ferlay J and Pisani P: Global cancer statistics 2002. CA Cancer J Clin 55: 74-108, 2005.

2 Mashberg A: Diagnosis of early oral and oropharyngeal squamous carcinoma: obstacles and their amelioration. Oral Oncol 36(3): 253-255, 2000.

3 Ryott M, Wangsa D, Heselmeyer-Haddad K, Lindholm J, Elmberger G, Auer G, Avall Lundqvist E, Ried T and MunckWikland E: EGFR protein overexpression and gene copy number increases in oral tongue squamous cell carcinoma. Eur J Cancer 45(9): 1700-1708, 2009.

4 Warnakulasuriya S, Reibel J, Bouquot J and Dabelsteen ES: Oral epithelial dysplasia classification systems: predictive value, utility, weaknesses and scope for improvement. J Oral Pathol Med 37(3): 127-133, 2008.

5 Veltman JA, Bot FJ, Huynen FC, Ramaekers FC, Manni JJ and Hopman AH: Chromosomal instability as an indicator of malignant progression in laryngeal mucosa. J Clin Oncol 18(8): 1644-1651, 2000.

6 Hanahan D and Weinberg RA: Hallmarks of cancer: the next generation. Cell 144(5): 646-674, 2011.

7 Yung-Hung Luo and Yuh-Min Chen: Recent advances in the development of mutant-selective EGFR inhibitors for non-small cell lung cancer patients with EGFR-TKI resistance. Transl Lung Cancer Res 3(6): 368-369, 2014.

8 Ai H, Barrera JE, Meyers AD, Shroyer KR and Varella-Garcia M: Chromosome aneuploidy precedes morphological changes and supports multifocality in head and neck lesions. Laryngoscope 111(10): 1853-1858, 2001.

9 El-Naggar AK, Chan JKC, Grandis JR, Takata T and Slootweg PJ: WHO Classification of head and neck tumours. IACR Publications, 4th edition, Vol 9, 2017.

10 Bockmuhl U, Schluns K, Kuchler I, Petersen S and Petersen I: Genetic imbalances with impact on survival in head and neck cancer patients. Am J Pathol 157: 369-375, 2000.
11 Braakhuis BM, Snijders PF, Keune WH, Meijer CM, RuijterSchippers HJ, Leemans CR and Brakenhoff RH: Genetic patterns in head and neck cancers that contain or lack transcriptionally active human papillomavirus. J Natl Cancer Inst 96: 998-1006, 2004.

12 Jin C,Jin Y, Wennerberg J, Annertz K, Enoksson J and Mertens F: Cytogenetic abnormalities in 106 oral squamous cell carcinomas. Cancer Genet Cytogen 164: 44-53, 2006.

13 Smeets SJ, Brakenhoff RH, Ylstra B, van Wieringen WN, van de Wiel MA, Leemans CR and Braakhuis BJ: Genetic classification of oral and oropharyngeal carcinomas identifies subgroups with a different prognosis. Cell Oncol 31(4): 291-300, 2009.

14 Taberna M, Mena M, Pavón MA, Alemany L, Gillison ML and Mesía R: Human papillomavirus-related oropharyngeal cancer. Ann Oncol 28(10): 2386-2398, 2017.

15 De Schutter H, Spaepen M, Mc Bride WH and Nuyts S: The clinical relevance of microsatellite alterations in head and neck squamous cell carcinoma: a critical review. Eur J Hum Genet 15: 734-741, 2007.

16 Gillison ML, D’Souza G, Westra W, Sugar E, Xiao W, Begum S and Viscidi R: Distinct risk factor profiles for human papillomavirus type 16-positive and human papillomavirus type 16-negative head and neck cancers. J Natl Cancer Inst 100: 407-420, 2008.

17 Fakhry C, Westra WH, Li S, Cmelak A, Ridge JA, Pinto H, Forastiere A and Gillison ML: Improved survival of patients with human papillomavirus-positive head and neck squamous cell carcinoma in a prospective clinical trial. J Natl Cancer Inst 100: 261-269, 2008.

18 Nakata Y, Uzawa N, Takahashi K, Sumino J, Michikawa C, Sato $\mathrm{H}$, Sonoda I, Ohyama Y, Okada N and Amagasa T: EGFR gene copy number alteration is a better prognostic indicator than protein overexpression in oral tongue squamous cell carcinomas. Eur $\mathbf{J}$ Cancer 47(15): 2364-2372, 2011.

19 Tsiambas E, Stavrakis I, Lazaris AC, Karameris A and Patsouris E: Evaluation of epidermal growth factor receptor gene and chromosome 7 alterations in squamous cell carcinoma of the larynx, using chromogenic in situ hybridization on tissue microarrays. J Laryng Otol 121(6): 563-570, 2007.

20 Sato H, Uzawa N, Takahashi K, Myo K, Ohyama Y and Amagasa T: Prognostic utility of chromosomal instability detected by fluorescence in situ hybridization in fine-needle aspirates from oral squamous cell carcinomas. BMC Cancer 10: 182-186, 2010.

21 Okafuji M, Ita M, Oga A, Hayatsu Y, Matsuo A and Shinzato Y: The relationship of genetic aberrations detected by comparative genomic hybridization to DNA ploidy and tumor size in human oral squamous cell carcinomas. J Oral Pathol Med 29(5): 226-231, 2000.

22 Tsiambas E, Mastronikolis NS, Lefas AY, Georgiannos SN, Ragos V, Fotiades PP, Tsoukalas N, Kavantzas N, Karameris A, Peschos D, Patsouris E, and Syrigos K: Chromosome 7 multiplication in EGFR-positive lung carcinomas based on tissue microarray analysis. In Vivo 31(4): 641-648, 2017.

23 Fiala O, Pesek M, Finek J, Minarik M, Benesova L, Sorejs O, Svaton M, Bortlicek Z, Kucera R and Topolcan O: Epidermal growth factor receptor gene amplification in patients with advanced-stage NSCLC. Anticancer Res 36(1): 455-460, 2016.

Received January 18, 2018

Revised February 15, 2018

Accepted February 26, 2018 